\title{
ASSESSMENT OF STRUCTURES SUBJECTED TO ACCIDENTAL ACTIONS USING CRISP AND UNCERTAIN FRAGILITY FUNCTIONS
}

\author{
Egidijus R. Vaidogas ${ }^{1}$, Virmantas Juocevičius ${ }^{2}$ \\ Dept of Occupational Safety \& Fire Protection, Vilnius Gediminas Technical University, \\ Sauletekio al. 11, LT-10223 Vilnius, Lithuania \\ E-mail: ${ }^{1}$ erv@st.vgtu.lt, ${ }^{2}$ virmantas.juocevičius@conserela.lt \\ Received 16 May 2008; accepted 08 Feb 2009
}

\begin{abstract}
An application of fragility functions to the assessment of potential damage due to an accidental action is analysed. The assessment is carried out as an estimation of the probability of a foreseeable damage event (damage probability). This probability is expressed as a mean value of a fragility function developed for the damage event under study. A Bayesian prior (posterior) distribution specified for this mean value is used as an estimate of the damage probability. The prior distribution is derived by transforming prior knowledge through the fragility function and "mapping" this knowledge on the scale of probability values. The technique of Bayesian bootstrap resampling is applied to update the prior distribution. The new information used for the updating consists of a relatively small number of experimental observations of the accidental action. To facilitate the updating, these observations are transformed into a fictitious statistical sample of fragility function values. The updating is first carried out with a fragility function which expresses aleatory uncertainty only. Then it is proposed how to perform the updating with the fragility function which quantifies both aleatory and epistemic uncertainty. This is done by discretising continuous distributions of the epistemic uncertainty related to values (parameters) of the fragility function. The proposed approach allows to utilise different sources of information for the damage assessment. A potential field of application of this approach is risk studies of hazardous industrial facilities.
\end{abstract}

Keywords: accidental action, damage, fragility function, uncertainty, bootstrap, Bayesian approach.

\section{Introduction}

The need to design structures which can withstand environmental and man-made hazards arises in many areas of structural engineering. An occurrence of hazard is called the accidental situation, that is, a situation, in which the structure can be damaged by accidental actions (ENV 1998, ISO 1998). The design for an accidental action may face uncertainties related to both characteristics of this action and response of structure to it. These uncertainties can be handled by means of a quantitative risk assessment (QRA). QRA can be seen as a methodology for systematic and consistent quantification and propagation of uncertainties related to rare and hazardous phenomena. QRA distinguishes between aleatory (stochastic) and epistemic (state-of-knowledge) uncertainties (e.g. Aven, Pörn 1998).

The design of structures for accidental actions includes the concept of fragility (Casciati, Faravelli 1991). Fragility is expressed quantitatively as a probability of structural failure (damage) conditional on a specific intensity of accidental action. A result of fragility analysis is a fragility function. Such a function is used mainly for earthquake risk assessment (e.g. Ellingwood 1998, 2001; Park et al. 1998). However, the concept of fragility function can also be adapted to predicting damage due to accidental actions of any kind.
In its simplest form, a fragility function quantifies the aleatory uncertainty. However, the incomplete knowledge of the behaviour of the structure subjected to a specific accidental action can cause that this function will be uncertain in the epistemic sense. An assessment of potential damage due to accidental action may require to handle aleatory and epistemic uncertainties related to both action and fragility function. These uncertainties can be quantified in line with the classical Bayesian approach to QRA (Aven, Pörn 1998; Vaidogas 2006, 2007b).

In this paper, the assessment of damage is understood as an estimation of probability of foreseeable damage event (briefly, damage probability). It is shown that an estimate of this probability can be expressed in the form of Bayesian prior (posterior) distribution. Two types of fragility function are used to specify the prior distribution: the function which expresses aleatory uncertainty only (crisp fragility function) and a function, the values of which are uncertain in the epistemic sense (uncertain fragility function).

The paper considers the case where the new data used for the updating of the prior distribution has the form of a small-size statistical sample. Elements of this sample are observations of potential accidental action recorded in experiment. They must be highly relevant to the specific situation of exposure to the action (briefly, exposure situation). The key idea of the paper is to transform the new data into values of a fragility function 
developed for the damage event under study. This transformation allows to estimate the damage probability with the small-size sample. The estimation is expressed as a problem of Bayesian statistical inference about a mean value of a fictitious population consisting of fragility function values.

\section{Fragility functions in damage assessment}

\subsection{Damage probability as a mean of fragility}

Possible damage due an accidental action can be represented by a finite set of $n_{d}$ random events $D_{i}(i=1,2, \ldots$, $n_{d}$ ), each standing for a foreseeable and specific damage phenomenon (structural failure). Probabilities (frequencies) of $D_{i}$ s can be grouped into a risk profile related to a particular accidental action and a specific exposure situation (Vaidogas 2005a, 2007; Jankovski, Atkočiūnas 2008; Vaidogas, Juocevičius 2008a; Zavadskas, Vaidogas 2008).

The probability of $D_{i}$ can be expressed in the form of a mean value:

$$
P\left(D_{i} \mid A A\right)=\int_{\text {all } \boldsymbol{y}} P\left(D_{i} \mid \boldsymbol{y}\right) \mathrm{d} F_{\boldsymbol{Y}}(\boldsymbol{y})=E\left(P\left(D_{i} \mid \boldsymbol{Y}\right)\right),
$$

where $A A$ is the random event of occurrence of an accidental action; $\boldsymbol{Y}$ is the random vector of action characteristics; $\boldsymbol{y}$ and $F_{Y}(y)$ are the value of $\boldsymbol{Y}$ and its joint distribution function, respectively; $P\left(D_{i} \mid \boldsymbol{y}\right)$ is the fragility function relating $\boldsymbol{y}$ to the probability of $D_{i}$. Arguments of the fragility function, $y$, are called the demand variables (e.g. Der Kiureghian 1999; Sasani et al. 2002; Vaidogas, Juocevičius 2008b).

The fragility function $P\left(D_{i} \mid \boldsymbol{y}\right)$ can be expressed as some function $p_{i}(\cdot)$ which takes on probability values:

$$
p_{i}(\boldsymbol{y})=P\left(D_{i} \mid \boldsymbol{y}\right) \text {. }
$$

This function allows to introduce a random variable

$$
\widetilde{P}=p_{i}(\boldsymbol{Y})=P\left(D_{i} \mid \boldsymbol{Y}\right) .
$$

A mean value of $\widetilde{P}$, subsequently denoted by $\mu$, is equal to the damage probability:

$$
\mu=E(\widetilde{P})=P\left(D_{i} \mid A A\right) .
$$

The main problem of an estimation of $\mu$ lies in the difficulty of selecting the distribution function $F_{Y}(y)$. Information on many accidental actions can be scarce; direct experimental data on a specific action can be unavailable at all. Further problem encumbering the estimation of $\mu$ can be uncertainties related to values of the fragility function $P\left(D_{i} \mid \boldsymbol{y}\right)$.

\subsection{Crisp and uncertain fragility functions}

The simplest fragility function $P\left(D_{i} \mid \boldsymbol{y}\right)$ expresses the aleatory uncertainty related to the event of interest (e.g. Fabbrocino et al. 2005, Lee, Rosowski 2006; Li, Ellingwood 2007). Such a function does not contain subjectively assigned information in the form of epistemic uncertainty measures (is purely objective). Most authors, however, use fragility functions containing subjective (judgmental) elements which can be treated as measures of epistemic uncertainty (Ellingwood 1998, 2001; Ghoicel et al. 1998; Liel et al. 2008; Ravindra 1995).

Der Kiureghian (1999) and Sasani et al. (2002) proposed to develop a fragility function by means of Bayesian limit state models. Such a function can be developed for $D_{i}$ if it is backed by one or several limit state functions $g_{i}(\boldsymbol{z}, \boldsymbol{y} \mid \boldsymbol{\theta})$, where $\boldsymbol{z}$ is the vector of variables describing the capacity of structural member and $\theta$ denotes the vector of model parameters. With a fixed (crisp) $\theta$, the fragility function expresses aleatory uncertainty only and is defined as

$$
P\left(D_{i} \mid \boldsymbol{y}\right)=P\left(g_{i}(\boldsymbol{Z}, \boldsymbol{y} \mid \boldsymbol{\theta}) \leq 0\right),
$$

where $\boldsymbol{Z}$ is the random vector quantifying aleatory uncertainty in $z$. A possible epistemic uncertainty in $\theta$ can be modelled by a random vector $\Theta$ with a joint probability density function (or, briefly, density) $\pi(\theta)$. This density is treated as a prior distribution and can be updated using the standard expression

$$
\pi(\theta \mid \text { data }) \propto L(\text { data } \mid \theta) \pi(\theta),
$$

where $L($ data $\mid \theta)$ is the likelihood function.

With the random $\Theta$, the fragility function $P\left(D_{i} \mid \boldsymbol{y}\right)$ becomes a random variable. Such a function will be called the uncertain fragility function and denoted by

$$
F_{i}(\boldsymbol{y} \mid \boldsymbol{\Theta}) \equiv P\left(D_{i} \mid \boldsymbol{y}, \boldsymbol{\Theta}\right)=P\left(g_{i}(\boldsymbol{Z}, \boldsymbol{y} \mid \boldsymbol{\Theta}) \leq 0\right) .
$$

The following consideration seeks to answer the question, how to estimate the damage probability $P\left(D_{i} \mid A A\right)$ with the crisp and uncertain fragility functions, namely, with $P\left(D_{i} \mid \boldsymbol{y}\right)$ and $P\left(D_{i} \mid \boldsymbol{y}, \boldsymbol{\Theta}\right)$.

\section{Bayesian estimation of damage probability with crisp fragility function}

\subsection{Fragility function \& prior knowledge}

Eqs (3) and (4) imply that the damage probability $P\left(D_{i} \mid A A\right)$ is an uncertain distribution parameter $\mu$ amenable to Bayesian inference. A prior density $\pi(\mu)$ of $\mu$ can be specified by utilizing the knowledge which is more or less relevant to the exposure situation under investigation. Such knowledge is often available to the engineer.

The prior knowledge, which is specific to a particular accidental action, may be expressed in the form of a mathematical model $\varphi(\cdot)$. This model relates characteristics of exposure situation to characteristics of accidental action:

$$
\boldsymbol{y}=\varphi(\boldsymbol{x} \mid \xi)
$$

where $\boldsymbol{x}$ is the vector describing characteristics of the exposure situation, in which an accidental action can occur; $\xi$ is the vector of parameters of $\varphi(\cdot)$. Examples of $\varphi(\cdot)$ are models used for predicting the pressure signal of an explosion in a given exposure situation (e.g. Casal 2008).

Components of $\xi$ may be uncertain in the epistemic sense. The exposure situation represented by $\boldsymbol{x}$ may be uncertain in the aleatory sense. This uncertainty can be modelled by a random vector $\boldsymbol{X}$ with an aleatory distribution function $F_{X}(x)$. 


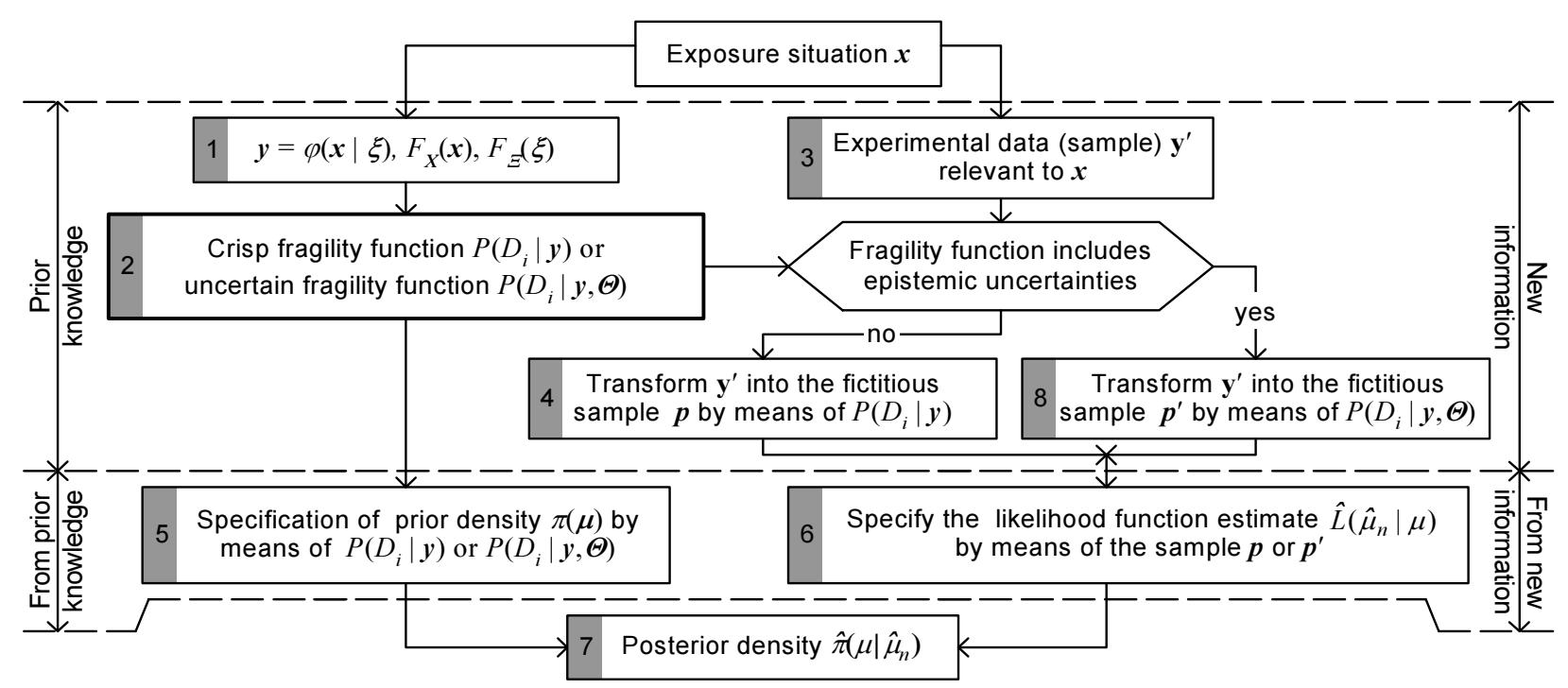

Fig. 1. The algorithm for the Bayesian estimation of the damage probability $P\left(D_{i} \mid A A\right)$ by means of the crisp and uncertain fragility functions $P\left(D_{i} \mid \boldsymbol{y}\right)$ and $P\left(D_{i} \mid \boldsymbol{y}, \boldsymbol{\Theta}\right)$

A part of the prior knowledge should be represented by the fragility function $p_{i}(y)$. Thus $p_{i}(\cdot)$ together with the model $\varphi(\cdot)$ form the main part of the prior knowledge (Blocks 1 and 2, Fig. 1).

\subsection{New information on accidental action}

The need to apply Bayesian inference to the estimation of the damage probability $P\left(D_{i} \mid A A\right)$ may stem mainly from a partial irrelevance of the prior knowledge to a particular exposure situation. The configuration of a structure exposed to an accidental action as well as the accident capable of inducing this action may be unique by a large margin. They may fit in the prior knowledge only partially. The source of the partial irrelevance may lie in the structure of the model $\varphi(\cdot)$ and/or data used to fit the distribution function $F_{X}(\boldsymbol{x})$ and estimate the parameters $\xi$ of $\varphi(\cdot)$.

The partial irrelevance of the prior knowledge expressed by $\varphi(\cdot)$ may require to combine this knowledge with the new data which is highly relevant to the exposure situation under analysis (Block 3, Fig. 1). In line with the Bayesian approach, the new data must be represented by the sample

$$
\mathbf{y}^{\prime}=\left\{y_{1}^{\prime}, y_{2}^{\prime}, \ldots, y_{j}^{\prime}, \ldots, y_{n}^{\prime}\right\} .
$$

This sample can be recorded in a series of $n$ experiments. Each of them should imitate a potential accident and differ from remaining ones in the sense of random sampling (e.g. Barnet 1991). The sample $\mathbf{y}^{\prime}$ should posses the property called by statisticians the "representativeness".

In theory, the size $n$ of $\mathbf{y}^{\prime}$ can be such that the model $\varphi(\cdot)$ will no longer be needed. With the large $n$, the action model $F_{Y}(y)$ can be fitted to $\mathbf{y}^{\prime}$ and the probability $P\left(D_{i} \mid A A\right)$ calculated by means of Eq (1). In practice, however, the cost of the experiments can cause that the size $n$ of $\mathbf{y}^{\prime}$ will be too small to apply the classical statistical approach to the selection of $F_{Y}(y)$. In the opposite case where the model $\varphi(\cdot)$ is sufficiently accurate and relevant to exposure situation, $F_{Y}(y)$ can be selected by a simulation-based propagation of aleatory and epistemic uncertainties through $\varphi(\cdot)$ (Vaidogas 2005b, 2007a, b). In the latter case, the estimation of $P\left(D_{i} \mid A A\right)$ will be possible without the sample $\mathbf{y}^{\prime}$. Thus the estimation of $P\left(D_{i} \mid A A\right)$ by applying both $\varphi(\cdot)$ and $\mathbf{y}^{\prime}$ can be seen as an intermediate problem located between two extreme problems: estimation solely by means of a large-size sample $\mathbf{y}^{\prime}$ and estimation based mainly on the application of $\varphi(\cdot)$.

The experiments producing the sample $\mathbf{y}^{\prime}$ may be unique and carried only once. Therefore it is probable that the Bayesian updating with $\mathbf{y}^{\prime}$ will be a single act, rather than a more or less constant process.

Given $\mathbf{y}^{\prime}$ and the crisp fragility function $P\left(D_{i} \mid \boldsymbol{y}\right)$, one can simplify the estimation of $P\left(D_{i} \mid A A\right)$ by introducing the following fictitious sample (Block 4, Fig. 1):

$$
\boldsymbol{p}=\left\{p_{1}, p_{2}, \ldots, p_{j}, \ldots, p_{n}\right\} .
$$

The $j$ th element of $\boldsymbol{p}$ is calculated by

$$
p_{j}=p_{i}\left(\boldsymbol{y}_{j}^{\prime}\right)=P\left(D_{i} \mid \boldsymbol{y}_{j}^{\prime}\right)
$$

A simple, one-dimensional visualization of the samples $\mathbf{y}^{\prime}$ and $\boldsymbol{p}$ is shown in Fig. 2.

The introduction of $\boldsymbol{p}$ turns the initial estimation of $P\left(D_{i} \mid A A\right)$ with the multi-dimensional sample $\mathbf{y}^{\prime}$ into a one-dimensional problem of statistical inference. Elements of $\boldsymbol{p}$ can be treated as realisations of the random variable $\widetilde{P}$, the mean value of which, $\mu$, is equal to $P\left(D_{i} \mid A A\right)$ (Eqs (3) and (4)). Consequently, $\boldsymbol{p}$ can be applied as new information to the updating of a prior density $\pi(\mu)$. 


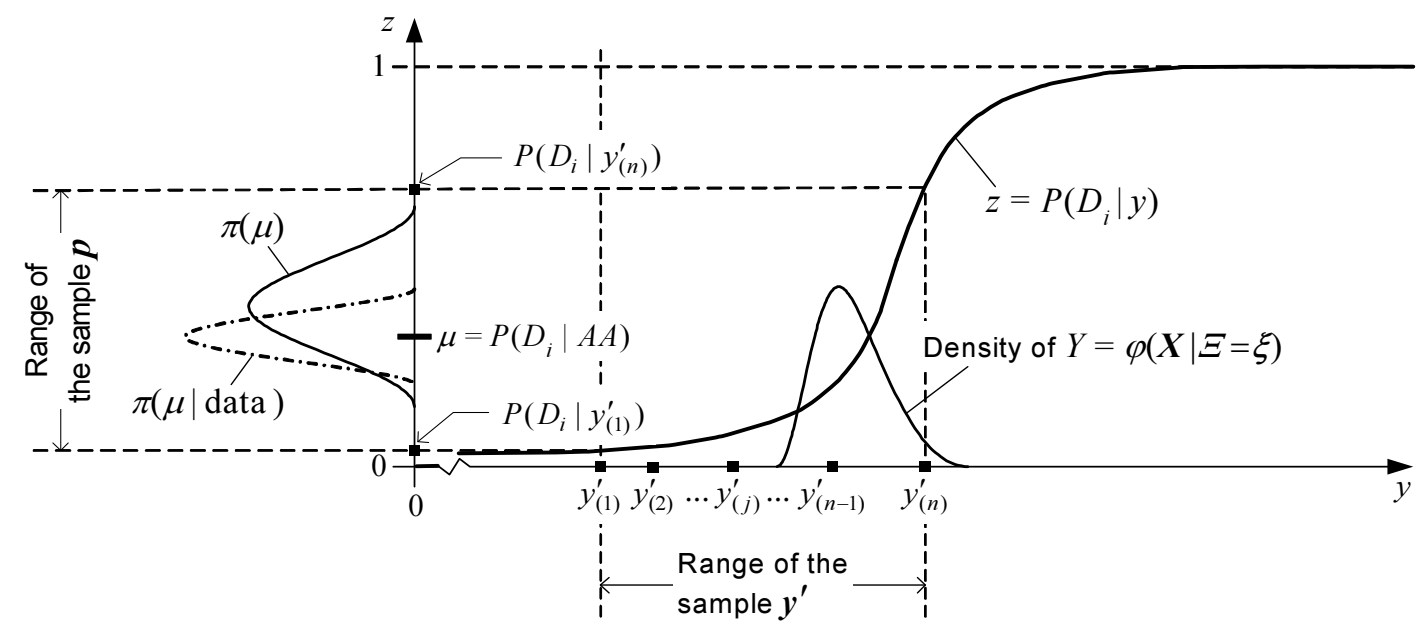

Fig. 2. One-dimensional visualization of the damage probability estimation with the crisp fragility function $P\left(D_{i} \mid y\right)$ $\left(y_{(j)}^{\prime}\right.$ is the $j$ th element of the ordered sample)

\subsection{Specifying the prior density with crisp fragility function}

Epistemic uncertainties related to the parameters of the model $\varphi(x \mid \xi)$ can be expressed by introducing a random vector $\Xi$ with a distribution function $F_{\Xi}(\xi)$. Then a replacement of the random vector $\boldsymbol{Y}$ by the random function $\varphi(\boldsymbol{X} \mid \Xi)$ will yield an epistemic random variable

$$
\tilde{M}=E_{\boldsymbol{X}}\left(p_{i}(\varphi(\boldsymbol{X} \mid \boldsymbol{\Xi}))\right)=\int_{\text {all } \boldsymbol{x}} P\left(D_{i} \mid \varphi(\boldsymbol{x} \mid \boldsymbol{\Xi})\right) \mathrm{d} F_{\boldsymbol{X}}(\boldsymbol{x}) .
$$

A value of $\tilde{M}$ is the damage probability at given $\xi$, namely, $E_{\boldsymbol{X}}\left(P\left(D_{i} \mid \varphi(\boldsymbol{X} \mid \xi)\right)\right)$. A density of $\widetilde{M}$ can be used as the prior density $\pi(\mu)$ quantifying the epistemic uncertainty in the damage probability $P\left(D_{i} \mid A A\right)$ (Block 5, Fig. 1).

\subsection{Updating the prior density of damage probability}

The standard Bayesian posterior density has the form

$$
\pi(\mu \mid \text { data }) \propto \pi(\mu) L(\text { data } \mid \mu),
$$

where "data" is represented by the samples $\boldsymbol{p}$ or $\mathbf{y}^{\prime}$ (Fig. 2). The usual Bayesian posterior $\pi(\mu \mid$ data) can be replaced by the estimated posterior (Vaidogas 2007b):

$$
\hat{\pi}(\mu \mid \text { data }) \propto \pi(\mu) \hat{L}_{B}(\text { data } \mid \mu),
$$

where $\hat{L}_{B}($ data $\mid \mu)$ is an estimate of the likelihood function (Block 6, Fig. 1). This estimate is based on a bootstrap estimation of the density of the pivotal quantity $\hat{\mu}_{n}-\widetilde{M}$, where $\hat{\mu}_{n}$ is the mean value of the sample $\boldsymbol{p}$. A possibility to replace $L($ data $\mid \mu)$ by $\hat{L}_{B}($ data $\mid \mu)$ was first suggested by Boos and Monahan (1986).

The estimate $\hat{L}_{B}($ data $\mid \mu)$ is calculated by

$$
\hat{L}_{B}\left(\hat{\mu}_{n} \mid \mu\right)=\frac{1}{B w} \sum_{b=1}^{B} \kappa\left(\frac{\left.2 \hat{\mu}_{n}-\mu-\hat{\mu}_{n b}^{\prime}\right)}{w}\right),
$$

where $B$ is the number of random bootstrap samples of the size $n$ generated from the empirical distribution func- tion $\hat{F}_{n}$ of the data $\boldsymbol{p} ; \hat{\mu}_{n b}^{\prime}$ is the mean value of the $b$ th bootstrap sample; $\kappa(\cdot)$ is the kernel function (e.g., density of standard normal distribution); $w$ is a bandwidth (window width, smoothing parameter).

The resulting estimate of the posterior density of $P\left(D_{i} \mid A A\right)$ is calculated by the following expression (Block 7, Fig. 1):

$$
\hat{\pi}\left(\mu \mid \hat{\mu}_{n}\right)=C\left(\hat{\mu}_{n}\right) \pi(\mu) \hat{L}_{B}\left(\hat{\mu}_{n} \mid \mu\right),
$$

where $C\left(\hat{\mu}_{n}\right)$ is the normalizing constant.

Practical implementation of the bootstrap-based updating procedure is relatively simple, as the estimates $\hat{L}_{B}\left(\hat{\mu}_{n} \mid \mu\right)$ and $\hat{\pi}\left(\mu \mid \hat{\mu}_{n}\right)$ can be computed almost automatically (details are given by Davison, Hinkley 1998, Davison et al. 1992, and Shao, Tu 1995).

\section{Estimation of damage probability with uncertain fragility function}

\subsection{Problem}

Now the estimation of the damage probability $P\left(D_{i} \mid A A\right)$ will be extended to the case of the uncertain fragility function $F_{i}(\boldsymbol{y} \mid \Theta)(\mathrm{Eq}(7))$. The epistemic uncertainty quantified by $F_{i}(\boldsymbol{y} \mid \Theta)$ can be averaged out or discretised by calculating the so-called bounds on fragility (Der Kiureghian 1999). However, such handling of the epistemic uncertainty leads to a partial loss of information expressed by $F_{i}(\boldsymbol{y} \mid \Theta)$. It makes sense to estimate $P\left(D_{i} \mid A A\right)$ by utilizing as much of this information as possible. This pertains to both specifying the prior density $\pi(\mu)$ and calculating the posterior density $\hat{\pi}\left(\mu \mid \hat{\mu}_{n}\right)$.

\subsection{Specifying the prior density with uncertain fragility function}

The prior of $\mu$ can be specified as described in Sec 3.3. Let us introduce an epistemic random variable 


$$
\begin{aligned}
\tilde{M}^{\prime} & =E_{\boldsymbol{X}}\left(F_{i}(\varphi(\boldsymbol{X} \mid \boldsymbol{\Xi}) \mid \Theta)\right) \\
& =\int_{\text {all } \boldsymbol{x}} F_{i}(\varphi(\boldsymbol{x} \mid \boldsymbol{\Xi}) \mid \Theta) \mathrm{d} F_{\boldsymbol{X}}(\boldsymbol{x}) .
\end{aligned}
$$

A value of $\tilde{M}^{\prime}$ is the damage probability corresponding to given values $\xi$ and $\theta$ of $\Xi$ and $\Theta$, namely, $E_{\boldsymbol{X}}\left(P\left(D_{i} \mid \varphi(\boldsymbol{X} \mid \xi), \boldsymbol{\theta}\right)\right)$. A density of $\tilde{M}^{\prime}$ serves naturally as the prior density $\pi(\mu)$ of the damage probability $P\left(D_{i} \mid A A\right)$ (Block 5, Fig. 1).

\subsection{Creating the sample of new data}

In case of the uncertain fragility function $F_{i}(\boldsymbol{y} \mid \Theta)$, an incorporation of the new data $\mathbf{y}^{\prime}$ into the updating of $\pi(\mu)$ becomes non-trivial. The sample $\mathbf{y}^{\prime}$ cannot be transformed into the sample $\boldsymbol{p}$ by means of the relation (11). For the $j$ th element $\boldsymbol{y}_{j}^{\prime}$ of $\mathbf{y}^{\prime}$ this relation yields an epistemic random variable

$$
\tilde{p}_{j}=F_{i}\left(y_{j}^{\prime} \mid \Theta\right) .
$$

This variable can be considered an imprecise observation (datum) (Fig. 3). Hence the uncertain fragility function $F_{i}(\boldsymbol{y} \mid \Theta)$ requires to update $\pi(\mu)$ using a set of $n$ imprecise "observations" $\tilde{p}_{j}$.

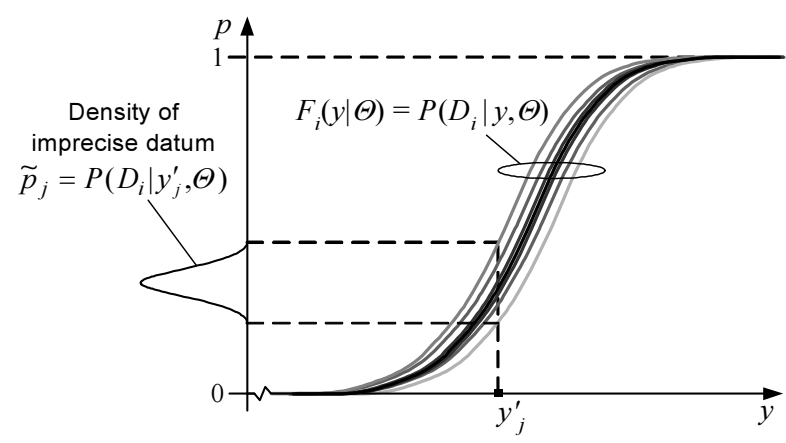

Fig. 3. One-dimensional visualization of an imprecise value of the fragility function $F_{i}(y \mid \Theta)$ related to the observation $y_{j}^{\prime}$

The problem of the Bayesian updating with imprecise data is known in the Bayesian statistical theory and related fields. Some authors model imprecise data with fuzzy numbers (Hryniewicz 2003; Huang et al. 2006; Viertl 2006). This approach it is not directly applicable to the case where data is represented as a set of epistemic random variables

$$
\widetilde{\boldsymbol{p}}=\left\{\widetilde{p}_{1}, \widetilde{p}_{2}, \ldots, \tilde{p}_{j}, \ldots, \widetilde{p}_{n}\right\} .
$$

An alternative approach, which matches the representation of data by $\widetilde{\boldsymbol{p}}$, is a quantification of uncertainty in individual data points using probability distributions (Siu, Kelly 1998 and references therein). However, this approach is based on averaging out the measures of epistemic uncertainty related to data points. Thus such an approach does not fit into the objective to utilize as much as possible of the information on epistemic uncertainty.
A well-elaborated theoretical basis and ready-to-use practical recipes for the updating of $\pi(\mu)$ with $\widetilde{\boldsymbol{p}}$ seem not to be available. Therefore one can start with a heuristic procedure which can provide some practical solution of the updating problem. The basic idea of the procedure is a discretisation of the uncertain fragility function $F_{i}(\boldsymbol{y} \mid \Theta)$. It can be represented as a family of fragility functions $F_{i}\left(\boldsymbol{y} \mid \Theta=\theta_{k}\right)$ with equal epistemic weights $w_{k}$, namely,

$$
\Phi=\left\{\left(F_{i}\left(\boldsymbol{y} \mid \Theta=\boldsymbol{\theta}_{k}\right), w_{k}\right), k=1,2, \ldots, m\right\},
$$

where $w_{k}=1 / m$ for each $k$.

An introduction of $\Phi$ allows to transform the new observation $\boldsymbol{y}_{j}^{\prime}$ into a set of $m$ observations

$$
p_{j k}=F_{i}\left(\boldsymbol{y}_{j}^{\prime} \mid \Theta=\theta_{k}\right)(k=1,2, \ldots, m) .
$$

An one-dimensional visualization of the transformation (21) is shown in Fig. 4. After this transformation is carried out for all $n$ elements of $\mathbf{y}^{\prime}$, a new sample consisting of $n \times m$ elements is obtained (Block 8, Fig. 1):

$$
\boldsymbol{p}^{\prime}=\left\{\left(p_{j k}, k=1,2, \ldots, m\right), j=1,2, \ldots, n\right\} .
$$

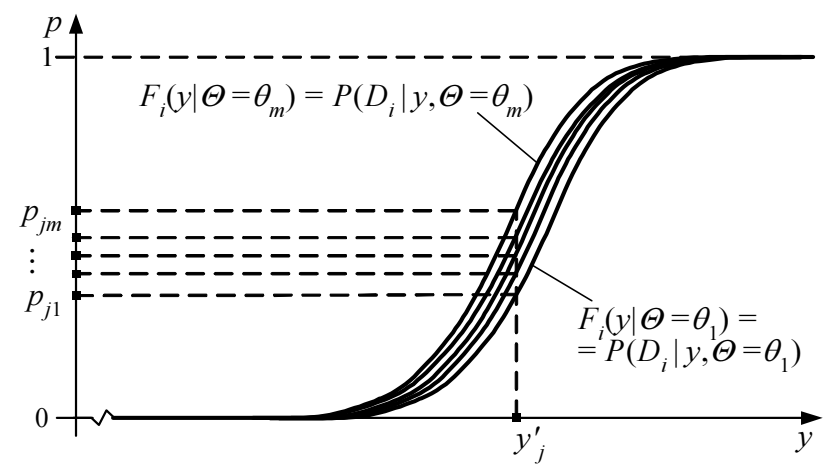

Fig. 4. Visualization of the data generated by the one-dimensional observation $y_{j}^{\prime}$

As the same family $\Phi$ is applied to transform each $\boldsymbol{y}_{j}^{\prime}$, all elements of $\boldsymbol{p}^{\prime}$ will have equal epistemic weights $1 / m$. This will assure that none of the elements will be preferred to others. The sample $\boldsymbol{p}^{\prime}$ can be applied to the updating of $\pi(\mu)$ in place of the sample $\boldsymbol{p}$ obtained with the crisp fragility function $(\mathrm{Eq}(11))$. The procedure of Bayesian bootstrap resampling can be used for this updating (Sec 3.4).

The larger is the number $m$ of members in the family $\Phi$ the closer is $\Phi$ to the continuous fragility function $F_{i}(\boldsymbol{y} \mid \Theta)$. In other words, the larger is $m$ the lesser amount of information related to the epistemic uncertainty in $F_{i}(\boldsymbol{y} \mid \cdot)$ is lost.

\section{Discretisation of uncertain fragility functions}

Function $F_{i}(\boldsymbol{y} \mid \Theta)$ can be transformed into $\Phi$ directly (at the level of its values related to specific $y$ ) and indirectly (at the level of the parameters $\Theta$ ). The choice of the discretisation method depends on the dimensionality of $\boldsymbol{y}$ and $\Theta$. 


\subsection{Discretisation at the level of uncertain parameters}

Where the vector $\Theta$ has a relatively small number of components, it makes sense to discretise the continuous prior/posterior density $\pi(\theta)$ of $\Theta$ rather than the fragility function $F_{i}(\boldsymbol{y} \mid \Theta)$ itself. The principle of such a discretisation is illustrated in Fig. 5. For a one-dimensional $\Theta$, the values $\theta_{k}$ can be calculated by

$$
\theta_{k}=F_{\Theta}^{-1}(k /(m+1)) \text { with } k \leq m,
$$

where $F_{\Theta}^{-1}(\cdot)$ is the inverse distribution function of $\Theta$. To satisfy the condition $\sum_{k} w_{k}=1$, the epistemic weights $w_{k}$ should be calculated by distributing the upper tail area $1-$ $F_{\Theta}\left(\theta_{m}\right)$, which is lost due to the discretisation, over all $\theta_{k} \mathrm{~s}$, namely,

$$
w_{k}=1 /(m+1)+1 /((m+1) m)=1 / m \text {. }
$$

In case where all components of $\Theta$ are independent random variables (are updated independently), the expression (23) can be generalized to a multi-dimensional case with relative ease. If, for example, $\Theta=\left(\Theta_{1}, \Theta_{2}\right)^{\mathrm{T}}$ and $\pi(\boldsymbol{\theta})=\pi\left(\theta_{1}\right) \pi\left(\theta_{2}\right)$, one can discretise $F_{i}(\boldsymbol{y} \mid \Theta)$ by introducing $m=m_{1} \times m_{2}$ values of $\Theta$, each defined by

$$
\begin{aligned}
\theta_{k}= & \left(\theta_{1 k_{1}}, \theta_{2 k_{2}}\right)^{\mathrm{T}} \\
& =\left(F_{\Theta_{1}}^{-1}\left(k_{1} /\left(m_{1}+1\right)\right), F_{\Theta_{1}}^{-1}\left(k_{2} /\left(m_{2}+1\right)\right)\right)^{\mathrm{T}},
\end{aligned}
$$

where $k_{1} \leq m_{1}$ and $k_{2} \leq m_{2}$. The equal epistemic weights $w_{k}$, which can be assigned to $\theta_{k} \mathrm{~s}$, are equal to $1 /\left(m_{1} \times m_{2}\right)$.

When components of $\Theta=\left(\Theta_{1}, \Theta_{2}\right)^{\mathrm{T}}$ are normally distributed, correlated random variables with the density $\pi\left(\theta_{1}, \theta_{2} \mid \mu_{1}, \mu_{2}, \sigma_{1}, \sigma_{2}, \rho\right)$, the discretisation can be carried out in two stages.

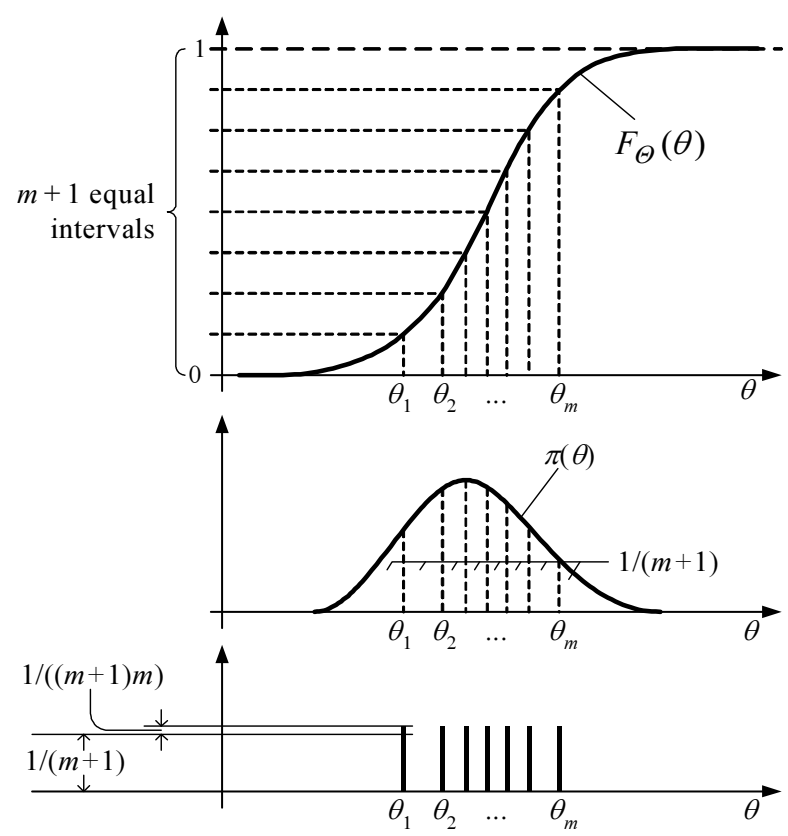

Fig. 5. Discretisation of the epistemic distribution of a fragility function parameter (the case of one-dimensional $\Theta$ )
Firstly, one can discretise a marginal distribution of $\Theta_{1}$. This will yield a set of the values

$$
\theta_{1 k}=F_{\Theta_{1}}^{-1}\left(k /(m+1) \mid \mu_{1}, \sigma_{1}\right)(k=1,2, \ldots, m),
$$

with the equal epistemic weights $1 / m$, where $F_{\Theta_{1}}^{-1}\left(\cdot \mid \mu_{1}, \sigma_{1}\right)$ is the inverse distribution function of a normal distribution with $\mu_{1}$ and $\sigma_{2}$. With the values $\theta_{1 k}$, the conditional distribution of $\Theta_{2}$ given $\Theta_{1}=\theta_{1 k}$ will be normal with the mean

$$
\mu_{2 k}=E\left(\Theta_{2} \mid \Theta_{1}=\theta_{1 k}\right)=\mu_{2}+\frac{\sigma_{2}}{\sigma_{1}}\left(\theta_{1 k}-\mu_{1}\right)
$$

and the variance

$$
\sigma_{2 k}^{2}=V\left(\Theta_{2} \mid \Theta_{1}=\theta_{1 k}\right)=\sigma_{2}^{2}\left(1-\rho^{2}\right) .
$$

Let us introduce conditional random variables $\Theta_{2 k} \sim N\left(\mu_{2 k}, \sigma_{2 k}\right) \quad$ with the distribution functions $F_{\Theta_{2 k}}\left(\theta_{2 k} \mid \mu_{2 k}, \sigma_{2 k}\right)$. With $\Theta_{1 k} \mathrm{~s}$, the continuous fragility function $F_{i}(\boldsymbol{y} \mid \Theta)$ can be replaced by a set of functions $F_{i}\left(\boldsymbol{y} \mid \theta_{1 k}, \Theta_{2 k}\right)(k=1,2, \ldots, m)$. Each of them will have one uncertain parameter $\Theta_{2 k}$ which can be discretised in the second stage into $m$ values by adopting the expression (23), namely,

$$
\theta_{2 k}=F_{\Theta_{2 k}}^{-1}\left(k /(m+1) \mid \mu_{2 k}, \sigma_{2 k}\right) \text { with } k \leq m .
$$

Thus the two-stage discretisation by means of Eqs (26) and (29) yields a total of $\mathrm{m}^{2}$ pairs $\left(\theta_{1 k}, \theta_{2 l}\right)$ and so a set of fragility functions $F_{i}\left(\boldsymbol{y} \mid \theta_{1 k}, \theta_{2 l}\right)$, each element of which has the epistemic weight of $1 / \mathrm{m}^{2}$.

\subsection{Direct discretisation}

In many cases $F_{i}(y \mid \Theta)$ is a univariate function ( $y$ has only one component), whereas the dimensionality of the parameter vector $\Theta$ is relatively large. An example of such a function was developed by Sasani et al. (2002) for a seismic fragility analysis of RC walls. This function has the form $F_{i}(y \mid \Theta)$, where $y$ is the significant peak ground acceleration and $\Theta$ has nine components.

The direct discretisation of the univariate function $F_{i}(y \mid \Theta)$ can start from segmenting its argument $y$. One can introduce a number $n_{y}$ of values $y_{1}, y_{2}, \ldots, y_{l}, \ldots$, $y_{n_{y}}$ equally distributed over the interval $\left[y_{1}, y_{n_{y}}\right]$. This interval should include the sample $\mathbf{y}^{\prime}$. Each $y_{l}$ generates an epistemic random variable

$$
\widetilde{P}_{l}=F_{i}\left(y_{l} \mid \Theta\right),
$$

with some distribution function $F_{\widetilde{P}_{1}}(p)$, where $p \in$ $[0,1]$. The continuous distribution of $P_{l}$ can be discretised using the expression (23):

$$
p_{l k}=F_{\tilde{P}_{l}}^{-1}(k /(m+1)) \text { with } k \leq m,
$$

where $F_{\widetilde{P}_{l}}^{-1}(\cdot)$ is the inverse distribution function of $\widetilde{P}_{l}$. The values $p_{l k}$ can be grouped together into the sets

$$
\Pi_{k}=\left\{p_{1 k}, p_{2 k}, \ldots, p_{n_{y} k}\right\}(k=1,2, \ldots, m) .
$$


All components of $\Pi_{k}$ are related to the same quantile level $k /(m+1)$. Hence the epistemic weight of each $\Pi_{k}$ is $1 / m$. The family $\Phi$ can be developed by fitting a univariate fragility function $F_{i}\left(y \mid \theta_{k}\right)$ to the individual sets $\Pi_{k}$. The weight of each $F_{i}\left(y \mid \theta_{k}\right)$ will still be $1 / m$.

\section{Illustrative example}

\subsection{Exposure situation \& prior knowledge}

An accidental explosion may occur inside a $30 \times 50 \mathrm{~m}^{2}$ zone within a plant running hazardous technology (Fig. 6). A cylindrical containment structure built of steel outside the zone and used for storage of flammable material can be damaged by this explosion.

The damage $D_{i}$ is a loss of containment due to a failure of the containment structure. The explosion is a distant one with respect to the exposed structure (Bulson 1997; Kala 2008). The fundamental natural period of the structure is assumed to be relatively small, as compared to the positive duration of the blast wave reflected by the structure. Thus the structure will respond to the positive overpressure only.

The prior knowledge is expressed by the model

$$
\begin{aligned}
y & =\varphi(\boldsymbol{x} \mid \xi) \\
& =\varphi^{\prime}\left(\xi\left(\frac{0,1 x_{1}^{1 / 3}}{r\left(x_{2}, x_{3}\right)}+\frac{0,43 x_{1}^{2 / 3}}{r^{2}\left(x_{2}, x_{3}\right)}+\frac{1,4 x_{1}}{r^{3}\left(x_{2}, x_{3}\right)}\right)\right),
\end{aligned}
$$

where $y$ is the peak positive overpressure of the wave reflected by the exposed structure; $r\left(x_{2}, x_{3}\right)$ is the standoff of the explosion (Fig. 6); $\varphi^{\prime}(\cdot)$ is the deterministic function used to transform the incident peak overpressure into the reflected one (see Kotlerovski 1995 for details); $\xi$ is the dimensionless factor used to adjust a standard TNT model to the explosive which can cause the accident under analysis.

The aleatory uncertainty related to $\varphi(x \mid \xi)$ is expressed by the random vector $\boldsymbol{X}=\left(X_{1}, X_{2}, X_{3}\right)^{\mathrm{T}}$, the components of which are the mass of explosive $X_{1} \sim \mathrm{N}(250 \mathrm{~kg}$, $30 \mathrm{~kg})$ and the coordinates of explosion centre $X_{2} \sim \mathrm{U}(0 \mathrm{~m}$, $30 \mathrm{~m}$ ) and $X_{3} \sim \mathrm{U}(0 \mathrm{~m}, 50 \mathrm{~m})$ ("N" and "U" denote the normal distribution and the uniform distribution, respectively). The uniform distribution of $X_{2}$ and $X_{3}$ implies that the explosion can occur with the same probability in each point of the $30 \times 50 \mathrm{~m}^{2}$ zone.

The epistemic uncertainty is introduced into the prior knowledge by assuming that the adjustment factor $\xi$ is uncertain in the epistemic sense. This uncertainty is modelled by the random variable $\Xi \sim \mathrm{L}(0.17975$; 0.11957 ) (lognormal distribution with the mode of 1,18 and the coefficient of variation of 0.12 ).

Further part of the prior knowledge is represented by the fragility function $p_{i}(\cdot)$ which relates the overpressure $y$ to the probability of $D_{i}$. In this example, a hypothetical fragility function $p_{i}(\cdot)$ is used. It is expressed by a normal distribution function $F_{i}\left(y \mid \Theta_{1}, \Theta_{2}\right)$ with uncertain mean $\Theta_{1}$ and uncertain variance $\Theta_{2}$. They are assumed to be independent and distributed as indicated in Table 1 .
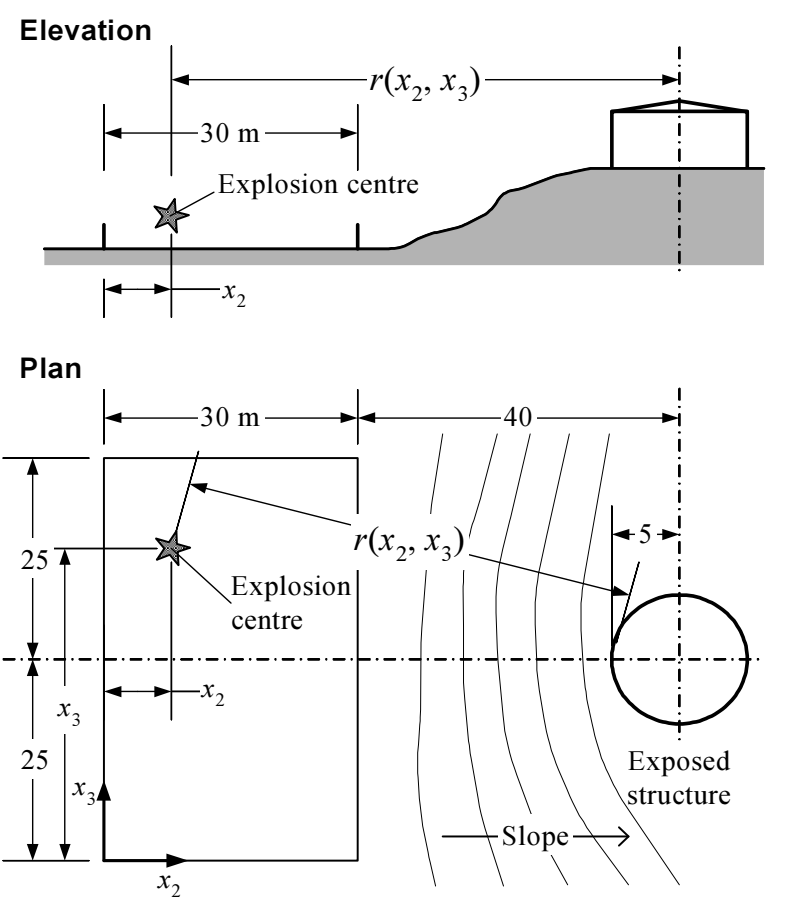

Fig. 6. Zone of the plant with potential hazard of accidental explosion

Table 1. Prior distributions of the parameters $\Theta_{1}$ and $\Theta_{2}{ }^{*}$

\begin{tabular}{c|c|c}
\hline $\begin{array}{c}\text { Parameter } \\
\text { of f. f. }\end{array}$ & $\begin{array}{c}\text { Type of } \\
\text { prior }\end{array}$ & Parameters of prior distribution \\
\hline$\Theta_{1}$ & Normal & $25 \mathrm{kPa}($ mean $) ; 1.5 \mathrm{kPa}(\mathrm{sd} . \mathrm{dv})$. \\
\hline$\Theta_{2}^{-1}$ & Gamma & $4($ shape $) ; 300^{-1}(\mathrm{kPa})^{-2}($ scale $)$ \\
\hline \multirow{3}{*}{ According to recommendations of Congdon $(2001: 19)$} \\
\hline
\end{tabular}

\subsection{Prior density of damage probability}

The prior density $\pi(\mu)$ can be specified by fitting it to the sample $\left\{\mu_{1}, \mu_{2}, \ldots, \mu_{l}, \ldots, \mu_{n_{l}}\right\}$, in which $\mu_{l}$ is an estimate of the mean $E_{\boldsymbol{X}}\left(p_{i}\left(\varphi\left(\boldsymbol{X} \mid \xi_{l}\right) \mid \theta_{l}\right)\right)$ at the given values $\xi_{l}$ and $\theta_{l}=\left(\theta_{1 l}, \theta_{2 l}\right)^{\mathrm{T}}$. To generate the sample of $\mu_{l} \mathrm{~s}$, the values $\xi_{l}$ were sampled by means of Monte Carlo simulation from $\mathrm{L}(0.17975 ; 0.11957)$. The values $\theta_{l}$ were sampled from the prior distributions given in Table 1. The sample size $n_{l}$ was chosen to be equal to 1000 . A normal density $\pi\left(\mu \mid 0.4232 ; 0.1082^{2}\right)$ was fitted to the sample of $\mu_{l} \mathrm{~s}$ as the prior density $\pi(\mu)$ (Fig. 7).

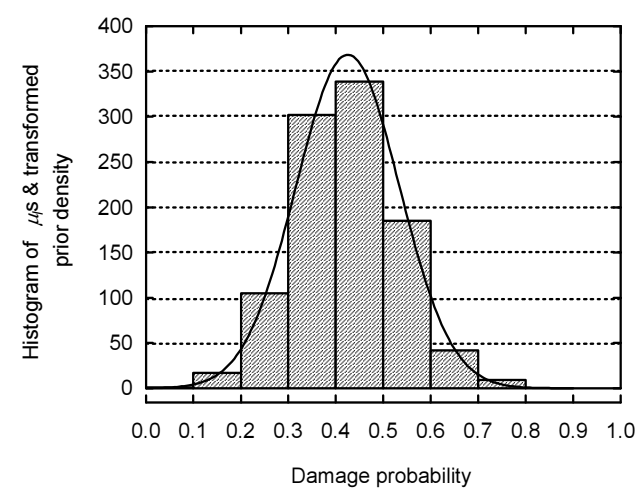

Fig. 7. Histogram of the sample $\left\{\mu_{1}, \mu_{2}, \ldots, \mu_{1000}\right\}$ and a normal density $\pi\left(\mu \mid 0.4232 ; 0.1082^{2}\right)$ fitted to this sample 


\subsection{New information used for updating}

The model $\varphi(x \mid \xi)$ is only partially relevant to the exposure situation shown in Fig. 6. It is valid for a distant free-field explosion on the ground which forms a horizontal plane. However, the ground between the zone and the exposed structure is sloping, the distance to the explosion centre is relatively small, and obstacles around the explosion centre created by process equipment can disturb the blast wave. Therefore, $\varphi(x \mid \xi)$ is suitable to specify the prior density $\pi(\mu)$; however, this density should be updated with new data.

The new data are expressed by a hypothetical sample with seven elements measured in $\mathrm{kPa}$ :

$\boldsymbol{y}^{\prime}=\left\{y_{1}^{\prime}, y_{2}^{\prime}, \ldots, y_{7}^{\prime}\right\}$

$=\{18,38 ; 13,89 ; 12,49 ; 18,12 ; 20,72 ; 17,16 ; 18,52\}$.

If the fragility function $p_{i}(\cdot)$ were a crisp one, $y^{\prime}$ could be transformed into the fictitious sample $\boldsymbol{p}$ and used for the updating of $\pi(\mu)$ (Sec 3.4). However, this example deals with the uncertain fragility function $F_{i}\left(y \mid \Theta_{1}, \Theta_{2}\right)$. To facilitate the Bayesian updating, this function will be replaced by a family of functions $F_{i}\left(y \mid \Theta=\theta_{k}\right)(k=1,2$, $\ldots, m)$, each having equal epistemic weight $1 / m$ (Sec 4.3). This will allow to create the new sample $\boldsymbol{p}^{\prime}$ defined by Eqs (21) and (22).

Table 2. The discretised values $\theta_{k}$ of uncertain parameters $\Theta_{1}$ and $\Theta_{2}\left(m_{1}=m_{2}=10\right)$

\begin{tabular}{ccc}
\hline$k_{1(2)} /\left(m_{1(2)}+1\right)$ & $\theta_{k_{1}}(\mathrm{kPa})$ & $\theta_{k_{2}}(\mathrm{kPa})^{-2}$ \\
\hline 0.09091 & 22.9972 & 0.00561556 \\
\hline 0.18182 & 23.6373 & 0.00735316 \\
\hline 0.27273 & 24.0931 & 0.00880000 \\
\hline 0.36364 & 24.4769 & 0.01016170 \\
\hline 0.45455 & 24.8287 & 0.01153080 \\
\hline 0.54545 & 25.1713 & 0.01297840 \\
\hline 0.63636 & 25.5231 & 0.01458690 \\
\hline 0.72727 & 25.9069 & 0.01648580 \\
\hline 0.81818 & 26.3627 & 0.01894310 \\
\hline 0.90909 & 27.0028 & 0.02277600 \\
\hline
\end{tabular}

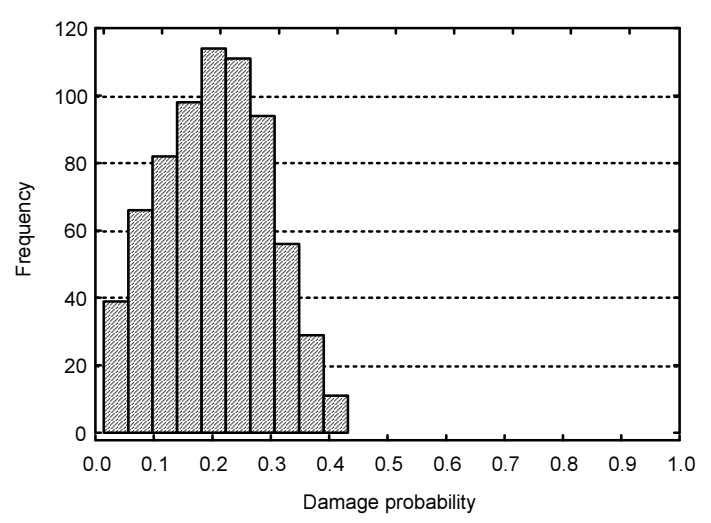

Fig. 8. Histogram of the sample $\boldsymbol{p}^{\prime}$ created by discretising the fragility function $F_{i}\left(y \mid \Theta_{1}, \Theta_{2}\right)$ and plugging in values of the initial sample $\boldsymbol{y}^{\prime}$
The discretisation of $F_{i}\left(y \mid \Theta_{1}, \Theta_{2}\right)$ was carried out at the level of uncertain parameters $\Theta_{1}$ and $\Theta_{2}$ with $m_{1}=$ $m_{2}=10$ (Sec 5.1). The discretised values of the uncertain parameters, $\theta_{k_{1}}$ and $\theta_{k_{2}}$, are given in Table 2. These values, together with the elements of the initial sample $\boldsymbol{y}^{\prime}$, yield the new data sample $\boldsymbol{p}^{\prime}$ consisting of the 700 values $F_{i}\left(y_{j}^{\prime} \mid \theta_{k_{1}}, \theta_{k_{2}}\right)\left(j=1,2, \ldots, 7 ; k_{1}, k_{2}=1,2, \ldots\right.$, 10). A histogram of $p^{\prime}$ is shown in Fig. 8. The mean $\hat{\mu}_{700}$ of $\boldsymbol{p}^{\prime}$ is equal to 0.20357 .

The sample $\boldsymbol{p}^{\prime}$ can be applied to estimation of the likelihood function $L\left(\hat{\mu}_{700} \mid \mu\right)$ and approximation of the posterior distribution of $P\left(D_{i} \mid A A\right)$.

\subsection{Posterior density of damage probability}

The estimate of the likelihood function, $L\left(\hat{\mu}_{700} \mid \mu\right)$, was obtained by applying the Gaussian kernel function $\kappa($.) (Davison, Hinkley 1998: 79). The number of bootstrap replications, $B$, necessary to generate the sample $\left\{\hat{\mu}_{n 1}^{\prime}, \hat{\mu}_{n 2}^{\prime}, \ldots, \hat{\mu}_{n B}^{\prime}\right\}$, was taken to be equal to 1000 . The choice of $B$ was based on the rules of thumb suggested by Efron and Tibshirani (1993: 52). The approximation of the posterior density, $\hat{\pi}\left(\mu \mid \hat{\mu}_{700}\right)$, computed at the bandwidth $w=0.05$ is shown in Fig. 9. This value of $w$ was chosen intuitively and the influence of $w$ on the estimates of the damage probability $P\left(D_{i} \mid A A\right)$ remains to be investigated. The approximation of the posterior density, $\hat{\pi}\left(\mu \mid \hat{\mu}_{700}\right)$, was obtained by means of Eq (16). The normalizing constant $C\left(\hat{\mu}_{700}\right)$ found by a numerical integration is equal to 0.6156 .

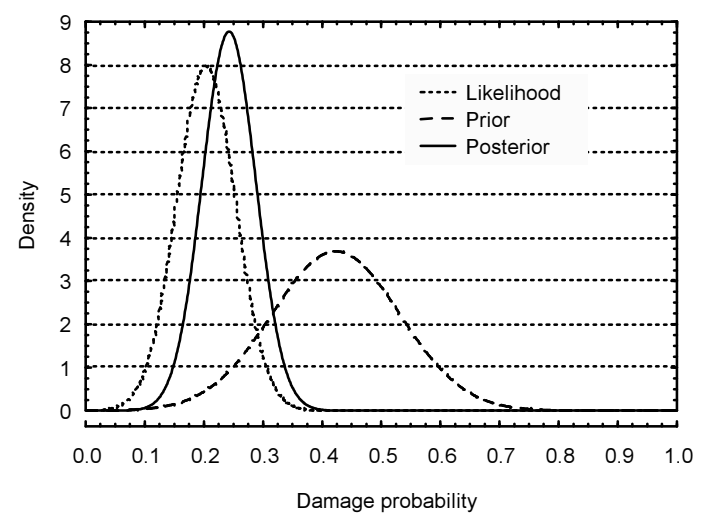

Fig. 9. Likelihood function estimate $L\left(\hat{\mu}_{700} \mid \mu\right)$, prior density $\pi(\mu)$ and estimate of posterior density $\hat{\pi}\left(\mu \mid \hat{\mu}_{700}\right)$ obtained with the bandwidth $w=0.05$

The approximation of the posterior density, $\hat{\pi}\left(\mu \mid \hat{\mu}_{700}\right)$, expresses updated epistemic uncertainty in the damage probability $P\left(D_{i} \mid A A\right)$. One can see that $\hat{\pi}\left(\mu \mid \hat{\mu}_{700}\right)$ is less inaccurate than the prior density $\pi(\mu)$. The degree of "inaccuracy" can be expressed by the ranges of non-conservative and conservative percentiles given in Table 3. The experimental records of the blast wave represented by the sample $y^{\prime}$ decreased the inaccuracy of the prior density $\pi(\mu)$ more than two times. One can anticipate that the conservative percentiles derived 
from $\hat{\pi}\left(\mu \mid \hat{\mu}_{700}\right)$ will be better understandable for the decision maker that the density $\hat{\pi}\left(\mu \mid \hat{\mu}_{700}\right)$ itself. Thus the decision concerning the potential damage event $D_{i}$ (failure of structure to contain hazardous material) can be made by applying these percentiles.

Table 3. Two pairs of percentiles derived from the prior density $\pi(\mu)$ and approximation of the posterior density $\hat{\pi}\left(\mu \mid \hat{\mu}_{700}\right)$

\begin{tabular}{ccc}
\hline \multirow{2}{*}{ Percentile } & \multicolumn{2}{c}{ Derived from the density } \\
\cline { 2 - 3 } & $\pi(\mu)$ & $\hat{\pi}\left(\mu \mid \hat{\mu}_{700}\right)$ \\
\hline $5^{\text {th }}$ & 0.2454 & 0.1675 \\
$95^{\text {th }}$ & 0.6010 & 0.3169 \\
Range & 0.3556 & 0.1494 \\
\hline $1^{\text {st }}$ & 0.1717 & 0.1365 \\
$99^{\text {th }}$ & 0.6747 & 0.3480 \\
Range & 0.503 & 0.2115 \\
\hline
\end{tabular}

\section{Conclusions}

An application of fragility functions to assessment of potential damage due to an accidental action has been considered. The result of this assessment was a probability of foreseeable damage event (damage probability). This probability was expressed and estimated as a mean value of a fragility function developed for the damage event under study. Bayesian prior and posterior distributions specified for this mean value were used as estimates of the damage probability. They were treated as measures of epistemic uncertainty related to this probability. The technique of Bayesian bootstrap resampling was used for updating the prior distribution.

The main emphasis was on an application of fragility functions within the scheme of Bayesian reasoning. These functions were used for utilising the prior knowledge about the accidental action and transforming this knowledge into the prior distribution. The new information applied to the updating of the prior distribution was expressed as a small-size sample consisting of experimental observations of the accidental action. The key idea of the paper was not to use these observations directly but to transform them into values of fragility function (new fictitious data). These values can be applied to the Bayesian updating.

The paper considered two cases of the updating: the case where the fragility function quantifies aleatory uncertainty only and the case where this function expresses both aleatory and epistemic uncertainty. A heuristic procedure was proposed to deal with the latter case. It was based on a discretisation of the continuous distributions which model epistemic uncertainty in fragility function parameters.

The approach proposed in the paper allows to utilise different sources of information to the assessment of damage due to accidental actions. An important feature of this approach is that the assessment can be carried out with a small-size sample of accidental action values recorded in the experiment. Such a sample can be not ame- nable to the classical statistical analysis. However, this sample can be used for damage assessing within the scheme of Bayesian reasoning. A potential field of application of the proposed approach are risk studies of hazardous industrial facilities like the ones described by Fabbrocino et al. (2005) and $\mathrm{Na}$ and Shinozuka (2008).

\section{References}

Aven, T.; Pörn, K. 1998. Expressing and interpreting the results of quantitative risk analyses. Review and discussion, Reliability Engineering \& System Safety 61(1): 3-10.

Barnett, V. 1991. Sample survey. Principles \& methods. London etc.: Edward Arnold.

Boos, D. D.; Monahan, J. F. 1986. Bootstrap methods using prior information, Biometrica 73(1): 77-83.

Bulson, P. S. 1997. Explosive loading on engineering structures. London etc: E \& FN Spon.

Casal, J. 2008. Evaluation of the effects and consequences of major accidents in industrial plants. Amsterdam etc: Elsevier.

Casciati, F.; Faravelli, L. 1991. Fragility analysis of complex structural systems. Taunton: Research studies press.

Congdon, P. 2000. Bayesian statistical modelling. Chichester et al.: Wiley.

Davison, A. C.; Hinkley, D. V. 1998. Bootstrap methods and their application. Cambridge: Cambridge university press.

Davison, A. C.; Hinkley, D. V.; Worton, B. J. 1992. Bootstrap likelihoods, Biometrica 79(1): 113-130.

Der Kiureghian, A. A. 1999. Bayesian framework for fragility assessment, in Proc of ICASP 8, 7-10 Juny, 2003, Sidney, Australia, 1003-1010.

Efron, B.; Tibshirani, R. J. 1993. An introduction to the bootstrap. New York: Chapman \& Hall.

Ellingwood, B. R. 1998. Issues related to structural aging in probabilistic risk assessment of nuclear power plants, Reliability Engineering \& System Safety 62(3): 171-183.

Ellingwood, B. R. 2001. Earthquake risk assessment of building structures, Reliability Engineering \& System Safety 74(3): 251-262.

ENV 1998. ENV 1991-2-7:1998. Eurocode 1: Basis of Design and Actions on Structures. Part 2-7: Accidental Actions due to Impact and Explosions. Brussels: CEN.

Fabbrocino, G.; Iervolino, I.; Orlando, F.; Salzano, E. 2005. Quantitative risk analysis of oil storage facilities in seismic areas, Journal of Hazardous Materials A123: 61-69.

Ghiocel, D. M.; Wilson, P. R.; Thomas, G. G.; Stevenson, J. D. 1998. Seismic response and fragility evaluation for an Eastern US NPP including soil-structure interaction effects, Reliability Engineering \& System Safety 62(3): 197214.

Hryniewicz, O. 2003. Bayes reliability tests with imprecise input data, in Proc of KONBIN 2003, 27-30 May 2003, Gdynia, Poland 2: 212-218.

Huang, H.-Z.; Zuo, M. J.; Sun, Zh.-Q. 2006. Bayesian reliability analysis for fuzzy lifetime data, Fuzzy Sets and Systems 157: $1674-1686$.

ISO 2394:1998(E). 1998. General principles on reliability for structures. Geneve: ISO.

Jankovski, V.; Atkočiūnas, J. 2008. MATLAB implementation in direct probability design of optimal trusses, Mechanika 6(74): $30-37$. 
Kala, Z. 2008. Fuzzy probability analysis of the fatigue resistance of steel structural members under bending, Journal of Civil Engineering and Management 14(1): 67-72.

Kotlerovskij, V. A. et al. 1995. Shelters of civil defence. Moscow: Stroijizdat (in Russian).

Lee, K. H.; Rosowsky, D. V. 2006. Fragility analysis of woodframe buildings considering combined snow and earthquake loading, Structural Safety 28(3): 289-303.

Li, Y.; Ellingwood, B. R. 2007. Reliablity of woodframe residential construction subjected to earthquakes, Structural Safety 29(4): 294-307.

Liel, A. B.; Haselton, C. B.; Deierlein, G. G.; Baker, J. W. 2008. Incorporating modeling uncertainties in the assessment of seismic collapse risk of buildings, Structural Safety (article in press).

Na, U. J.; Shinozuka, M. 2008. Simulation-based seismic loss estimation of seaport transportation system, Reliability Engineering \& System Safety (article in press).

Park, Y. J.; Hofmayer, C. H.; Chokshi, N. C. 1998. Survey of seismic fragilities used in PRA studies of nuclear power plants, Reliability Engineering \& System Safety 62(3): 185-195.

Ravindra, M. K. 1995. Extreme wind risk assessment, in Probabilistic Structural Mechanics Handbook. New York etc.: Chapman\&Hall, 429-464.

Sasani, M.; Der Kiureghian, A.; Bertero, V. V. 2002. Seismic fragility of short period reinforced concrete structural walls under neat source ground motions, Structural Safety 24(2): 123-138.

Shao, J.; Tu, D. 1995. The jackknife; bootstrap. New York etc.: Springer.

Siu, N. O.; Kelly, D. L. 1998. Bayesian parameter estimation in probabilistic risk assessment, Reliability Engineering \& System Safety 62(1): 89-116.
Vaidogas, E. R. 2005a. Explosive damage to industrial buildings: assessment by resampling limited experimental data on blast loading, Journal of Civil Engineering and Management 11(4): 251-266.

Vaidogas, E. R. 2005b. Actions imposed on structures during man-made accidents: prediction via simulation-based uncertainty propagation, Journal of Civil Engineering and Management 11(3): 225-242.

Vaidogas, E. R. 2006. First step towards preventing losses due to mechanical damage from abnormal actions: Knowledge-based forecasting the actions, Journal of Loss Prevention in the Process Industries 19(3): 375-385.

Vaidogas, E. R. 2007a. Handling uncertainties in structural fragility by means of the Bayesian bootstrap resampling, in Proceedings (CD-ROM) of Int. Conf. ICASP 10. 1-3 August, 2007, Tokyo, Japan. London: Taylor \& Francis.

Vaidogas, E. R. 2007b. Prediction of accidental actions likely to occur on building structures. An approach based on stochastic simulation. Vilnius: Technika.

Vaidogas, E. R.; Juocevičius, V. 2008a. Sustainable development and major industrial accidents: the beneficial role of risk-oriented structural engineering, Technological and Economic Development of Economy 14(4): 612-627.

Vaidogas, E. R.; Juocevičius, V. 2008b. Reliability of a timber structure exposed to fire: estimation using fragility function, Mechanika 5(73): 35-42.

Viertl, R. 2006. Univariate statistical analysis with fuzzy data, Computational Statistics \& Data Analysis 51: 133-147.

Zavadskas, E. K.; Vaidogas, E. R. 2008. Bayesian reasoning in managerial decisions on the choice of equipment for prevention of industrial accidents, Engineering Economics 60(5): 32-40.

\section{AVARINIŲ APKROVU VEIKIAMŲ KONSTRUKCIJŲ VERTINIMAS TAIKANT TIKSLIAS IR NEAPIBRĚŽTAS PAŽEIDŽIAMUMO FUNKCIJAS}

\section{E. R. Vaidogas, V. Juocevičius}

\section{Santrauka}

Analizuojamas pažeidžiamumo funkcijų taikymas vertinant potencialius statybinių konstrukcijų pažeidimus avariniais poveikiais. Vertinimas atliekamas skaičiuojant galimos konstrukcijos pažaidos tikimybę. Ši tikimybe yra išreiškiama vidutine pažeidžiamumo funkcijos reikšme. Ta funkcija yra formuojama analizuojamam pažaidos ivykiui. Apriorinis ir aposteriorinis Bajeso skirstiniai yra taikomi pažaidos tikimybės reikšmei vertinti. Apriorinis skirstinys yra gaunamas pasinaudojant turima informacija apie avarini poveiki ir transformuojant šią informacija per pažeidžiamumo funkcija. Aposteriorinis skirstinys yra gaunamas pasitelkiant nauja, eksperimentinę informaciją apie avarini poveiki. Aposterioriniam skirstiniui gauti taikomas kartotinio statistinio ėmimo (būtstrapo) metodas. Naują informaciją sudaro eksperimentiniai avarinio poveikio charakteristikų matavimai, kurie tiksliai atitinka konstrukcijos ekspozicijos tiriamo poveikio situaciją. Apriorinis ir aposteriorinis skirstiniai išreiškia episteminį neapibrěžtumą vertinamos pažaidos tikimybès reikšmès atžvilgiu. Šie skirstiniai yra gaunami taikant tiek pažeidžiamumo funkciją kuri išreiškia tik stochastini neapibrěžtumą, tiek funkciją, kurios reikšmès yra neapibrěžtos epistemine prasme. Potenciali siūlomo metodo taikymo sritis yra pavojingų pramoninių objektų rizikos vertinimas.

Reikšminiai žodžiai: avarinis poveikis, pažaida, pažeidžiamumo funkcija, neapibrež̌tumas, kartotinio statistinio ėmimo metodas, Bajeso požiūris.

Egidijus Rytas VAIDOGAS is PhD, Professor of Dept of Occupational Safety and Fire Protection at Vilnius Gediminas technical university, Lithuania. His major research interests: structural reliability, design of structures for accidental loads, application of risk analysis to safety assurance of structures.

Virmantas JUOCEVIČIUS is a PhD student at Dept of Occupational Safety and Fire Protection at Vilnius Gediminas technical university, Lithuania. BSC (2005), MSc (2007) from VGTU. Research interests include fire safety engineering, design of structures for accidental loads, statistical modelling of structures. 